\title{
Etik Liderliğin Belirleyicileri Olarak Kişilik, Örgüt Kültürü ve Dini Yönelim: Antalya'daki Dört ve Beş Yıldızlı Otellerde Bir Uygulama*
}

\section{Determinants of Ethical Leadership as Personality, Organization Culture and Religious Orientation: Sample of Four and Five Stars Hotels in Antalya}

\author{
Yrd. Doç. Dr. Faruk Kerem ŞENTÜRK \\ Düzce Üniversitesi \\ İşletme Fakültesi \\ E-posta: keremsenturk@duzce.edu.tr \\ Orcid Id: 0000-0002-3055-0797
}

Öz

Araştırmanın temel amacı kişilik, örgüt kültürü ve dini yönelim değişkenlerinin etik liderlik oluşumundaki etkilerini belirlemektir. Araştırmanın evrenini Antalya'da faaliyet gösteren 4 ve 5 yıldızlı otel işletmelerinde farklı kademelerde çalışan 405 yönetici oluşturmaktadır. Araştırma yöntemi nicel olmakla birlikte veri toplama tekniği olarak anket kullanılmıştır. Geliştirilen etik liderlik ölçeğinin yapılan faktör analizi sonucunda tek faktör altında toplandığı sonucuna ulaşılmıştır. Değişkenler arasındaki ilişkileri tespit etmeye yönelik yapılan regresyon analizleri sonucunda ise kişilik özelliklerinden uyumluluk ve açıklık özelliklerinin, örgüt kültürü tiplerinden klan kültürünün etik liderlik ile ilişkili olduğu tespit edilmiştir. Dini yönelim açısından ise hem içsel dini yönelim hem de dışsal dini yönelimin etik liderlik ile ilişkili olduğu sonucuna ulaşılmıştır.

Anahtar Kelimeler: Etik liderlik, Örgüt kültürü, Kişilik özellikleri, Dini yönelim

\begin{abstract}
The main aim of this study is to determine the effects of personality, organizational culture and religious orientation on the formation of ethical leadership. Sample of this study consists of 405 managers, who work in various departments of 4 and 5 star hotels in Antalya region. Research method was quantitative and survey was used as data collection technique. As a result of the factor analysis, it has been determined that the ethical leadership scale items gathered under single factor. In consequence of regression analyses, it has been found that the personality traits such as agreeableness and openness, clan culture as an organizational type, intrinsic and extrinsic religious orientation have an effect on ethical leadership behaviors.
\end{abstract}

Keywords: Ethical leadership, Organization culture, Personality traits, Religious orientation

\footnotetext{
* Bu çalışma Faruk Kerem Şentürk'ün "Etik Liderliğin Belirleyicileri Olarak Kişilik, Örgüt Kültürü, Dini Yönelim ve Çevresel Faktörler: Antalya'daki Dört ve Beş Yıldızı Otellerde Bir Uygulama” isimli doktora tezinden türetilmiştir.
} 


\section{Giriş}

Yaşanan birçok değişim ve teknolojik alandaki gelişmeler insanların yemek yeme veya uyku alışkanlıklarından tutun, olaylara bakış açısına kadar neredeyse her alanda hayatını etkilemektedir. Genel anlamda yaşanan gelişmeler toplumun refah düzeyini artırmaya yönelik olsa da birçok sıkıntıyı da beraberinde getirmektedir. Ortaya çıkan problemleri çözmede klasik liderlik yaklaşımları etkisiz kalmakta ve yeni liderlik türlerine intiyaç duyulmaktadır. Bu ihtiyaca dayalı olarak, yaşanan olumsuz sosyal ve kültürel gelişmeler de göz önünde bulundurularak "etik bir lider olabilmek veya böyle bir lider yetiştirebilmek için ne gibi faktörlerin etkisi olabilir" sorusuna araştırma kapsamında cevap aranmıştır. Uzun literatür taramaları sonucunda bireyin kendisini ifade etme şekli olan kişilik özellikleri, hayata yön veren temel değişkenlerden biri olan dini yönelim, çalışılan işletmenin sahip olduğu kültür tipi temel değişkenler olarak ele alınmış ve etik liderlik oluşumuna etkisi değerlendirilmiştir.

\section{Literatür Taraması}

Liderlik kavramının tarihsel geçmişine bakıldığında liderin sahip olduğu özelliklere odaklanan bir anlayıştan, takipçileri de dikkate alan davranışsal teorilere, bu noktadan çevresel değişkenleri de hesaba katmaya çalışan durumsal teorilere doğru yol aldığı görülmektedir. Ancak günümüzdeki teknolojik değişim ve bunun sosyolojik yansımaları o kadar hızlı gerçekleşmekte ki bireylerin liderlik kavramına bakış açısı da farklılaşmaktadır. Dolayısıyla günümüzde yeni liderlik türleri başlığı altında birçok liderlik tipolojisi teorik çerçevede incelenmeye başlanmıştır. Bu liderlik tiplerinden biri de yozlaşmanın, egoist ve otokratik davranışların iş dünyasında sık görülmesi sonucu intiyaca binaen ortaya çıkan etik liderliktir. Etik bir liderlik tipolojisinin ortaya konması için birçok faktör bulunmakla birlikte araştırmamız kapsamında öncelikle etik liderliğe yönelik literatür irdelenecek sonrasında etik liderliğin oluşumuna etki ettiği düşünülen kişilik, örgüt kültürü ve dini yönelim konularına yönelik literatür değerlendirilecektir.

\subsection{Etik Liderlik}

Genel olarak yapılan araştırmalarda liderlerin işletme içinde ve çalışanlar üzerindeki pozitif etkilerine yer verilmektedir. Liderlerin kötü davranışlarının çalışanlar üzerinde işi bırakma, iş ve yaşamdan tatmin olma düzeyinin düşmesi, örgütsel bağlılıkta düşüş, aile ve iş yaşamında çatışma yaşanması ve psikolojik stres gibi birçok olumsuz sonuçları olduğu belirtilmektedir (Tepper, 2000). Tannenbaum ve Schmidt (1973) bir liderin, elindeki gücü kullanırken sahip olduğu değer sisteminden, astlarına olan güveninden, kendilerine has liderlik eğilimleri ve belirsiz durumlarda hissettikleri güvenlik duygusundan etkilendiğini belirtmektedir. Bu noktada günümüzün liderlik anlayışındaki değişim ile birlikte takipçilerin, iş arkadaşlarının, denetçilerin araştırma kapsamına dahil edilmesi ve kamu, özel sektör ve kar amacı olmayan örgütlerde dahi liderliğin etkileri üzerine çalışmalar yapılması (Avolio vd., 2009) liderliğin etik boyutlarının da dikkate alınmasında etkili olmuştur. Eisenbeiss (2012) etik liderlik konusunun önemli olduğunu belirtmek ile birlikte sosyal bilimler alanında etik liderlik ile ilgili yeterli nitelikte çalışma olmadığına vurgu yapmaktadır.

Brown ve arkadaşları (2005: 120) etik liderliği "kişisel eylemler ve kişilerarası ilişkilerde normatif olarak uygun davranış gösterilmesi ve liderin takipçilerine böyle bir davranışı karşılıklı iletişim, güçlendirme ve karar alma ile teşvik etmesi” olarak tanımlamaktadır. Güney (2012: 344) ise etik lideri "iş ahlakı ilkelerini kurum ya da toplum kültürüne yerleştiren, izleyenlerine insani değerlerle yaklaşan, hak, hukuk ve adalet kavramlarını yönetim anlayışının temeline koyan kişi” olarak tanımlanmaktadır. 
Brown ve Treviño (2006) etik liderliğin temel vurgusunun ahlaki yönetim ve ahlaki standartları olduğunu belirtirken, otantik liderliğin özgünlük ve öz-farkındalığı, ruhsal liderliğin vizyon belirleme ve umut/inanç gibi değerleri iş ortamında vurguladığını ve dönüşümcü liderlik anlayışının vizyonu, değerleri ve entelektüel teşvikleri vurguladığını belirtmektedir. Bu şekilde etik liderlik kavramının temel vurgusunun diğer liderlik türlerinden farklıı̆̆ını ortaya koymaktadır.

Trevino ve diğerleri (2000) etik bir liderin çalışanları üzerindeki etik lider itibarını artırması gerektiğini, bununda bireyin hem ahlaki bir kişilik olarak hem de ahlaki bir yönetici olarak takipçileri üzerinde güçlü bir algı oluşturması yoluyla olacağını belirtmektedir. Van den Akker ve diğerleri (2009) araştırmaları sonucunda çalışanların etik davranışlar sergileyen liderlere güven düzeylerinin yüksek olduğunu belirtmektedir. Bireylerin gelişiminde yaradılış itibari ile bazı mizaç özelliklerinin yanı sıra hayatlarındaki tüm sosyal etkileşimleri sonucu oluşan karakterlerinin de önemli düzeyde etkileri bulunmaktadır. Bu bağlamda liderlik konusunun kişilik özellikleri açısından ele alınması da gerekmektedir.

\subsection{Kişilik}

Allport'a göre kişilik, psikolojik bakımdan, bir insanın gerçekten olduğu ve yaptığı; birey içindeki dinamik örgütlenme; insanın çevresine, kendisine özgü uyumunu sağlayan psikofizik sistemlerdir. Ayrıca Allport bireyin kendisine özgü tekliğinin ve kendisine özgü bir olgu teşkil edişini de kişilik olarak tanımlamaktadır (Dönmezer, 1982: 144145). Kişilik, bir insanın duyuş, düşünüş, davranış biçimlerini etkileyen etmenlerin kendine özgü görüntüsüdür (Karabatı, 2012: 195). Kişilik, bireyin çeşitli durumlardaki özel davranışlarda ifadesini bulan yapısal ve dinamik özelliklerinin tümüdür ve bu özellikler onu başkalarından ayıran sürekli ve tutarlı olan davranışlarıdır (Erkal, 2009: 250-251).

Kişiliği açıklamaya çalışan önemli yaklaşımlardan biri de ayırıcı özellikler yaklaşımıdır. Ayırıcı özellikler benzer durumlarda yinelenen, yerine oturmuş davranış biçimleridir ve daha somut olduğu gibi günlük deneyimlerle de uyumludur $(\mathrm{GH}, 1983$ : 2382). Ayırıcı özellikler yaklaşımı iki temel varsayıma dayanmaktadır. İlk varsayım kişilik özelliklerinin zaman içinde değişmez olduğu, kararlılık gösterdiği düşüncesine dayanırken ikinci varsayıma göre ise kişinin sahip olduğu bu özelliklerin farklı durumlarda da tutarlılık göstereceği düşüncesine dayanmaktadır (İnanç ve Yerlikaya, 2012: 251).

Bireylerin sahip olduğu özellikleri ve durumları sınıflamaya yönelik birçok çalışma yapılmıştır. Ayırıcı özellikler yaklaşımının öncülerinden Allport ve Odbert (1936) kısaltılmamış bir sözlük üzerinde yaptıkları araştırma sonucunda bireyi tarif eden 18.000 İngilizce kelime tespit etmişlerdir ki bu İngiliz diline ait sözlüğün yaklaşık \%5'ine tekabül etmektedir (Atkinson vd., 2010: 434). Daha sonra Cattell $(1945,1947)$ uzun yıllar süren çalışmalar sonucunda faktör analizini kullanarak kişiliğin temel özelliklerini keşfetmeye çalışmış ve bu özellikleri 16 temel başlık (Sıcaklık, Akıl Yürütme, Duygusal Kararlııı, Baskınlık, Canlııı, Kurallara Bağlılık, Sosyal Girişkenlik, Hassaslık, İhtiyatlılık, Dalgınlık, İçtenlik, Endişe, Değişikliğe Açıklık, Kendine Yetme, Mükemmeliyetçilik, Gerginlik) (İnanç ve Yerlikaya, 2012: 267) altında toplamıştır. Cattell'in ortaya koyduğu değişkenler birçok araştırmacı tarafından ele alınmış ve faktörleşme düzeyleri üzerinde birçok çalışma yapılmıştır. Bu değişkenlerin genel olarak beş faktör üzerinde yoğunlaştığı sonucu ortaya çıkmıştır (Digman, 1989; Digman, 1990; Goldberg, 1990; Goldberg, 1992; Tupes ve Christal, 1992; Costa ve McCrae, 1992). 
Tablo 1: Beş Temel Kişilik Faktörü

\begin{tabular}{|c|c|c|}
\hline $\begin{array}{c}\text { Beş Temel Kişilik } \\
\text { Bileşeni }\end{array}$ & İçeriği & Sifatlar \\
\hline $\begin{array}{l}\text { Dışadönüklük } \\
\text { (Extraversion) }\end{array}$ & $\begin{array}{l}\text { Bireylerin } \\
\text { ilişkilerindeki } \\
\text { rahatlık derecesini } \\
\text { gösteren boyuttur. }\end{array}$ & $\begin{array}{l}\text { Bu bireyler dişa kolay açılabilen, sosyal kararlı, } \\
\text { konuşkan ve aktif özelliklere sahiptir. Bunun } \\
\text { karşıtı olan içedönük kişilik tipi ise sessiz, } \\
\text { utangaç, çekingen, ihtiyatlı gibi özelliklere } \\
\text { sahiptir. Içedönük kişiler tek başına olmaktan } \\
\text { mutluluk duyarken dışadönük kişiler diğer } \\
\text { insanlarla birlikte olmaktan mutluluk duyarlar. }\end{array}$ \\
\hline $\begin{array}{l}\text { Nörotisizm } \\
\text { (Neuroticism) }\end{array}$ & $\begin{array}{l}\text { Bireyin strese } \\
\text { dayanıklılık } \\
\text { ölçüsüdür. }\end{array}$ & $\begin{array}{l}\text { Yaşamında güvenli, sakin, endişeli olmayan } \\
\text { özellikleri taşırken, karşıt boyutundaki bireyler } \\
\text { içine dönük, kararsız, endişeli ve mutsuzdurlar. }\end{array}$ \\
\hline $\begin{array}{l}\text { Deneyime Açılık } \\
\text { (Openness to } \\
\text { Experience). }\end{array}$ & $\begin{array}{l}\text { İnsanların ilgilerinin } \\
\text { genişliğini ve } \\
\text { yeniliklerden } \\
\text { büyülenme } \\
\text { derecesini belirtir. }\end{array}$ & $\begin{array}{l}\text { Hassas, esnek, yaratıcı, meraklı özellikleri içerir. } \\
\text { Karşıt boyutu ise değişime dirençli, yeni fikirlere } \\
\text { kapalı ve dar görüşlü gibi özellikleri barındırır }\end{array}$ \\
\hline $\begin{array}{l}\text { Uyumluluk } \\
\text { (Agreeableness) }\end{array}$ & $\begin{array}{l}\text { Bu boyut bireyin } \\
\text { diğerleri ile uyum } \\
\text { içinde olmasındaki } \\
\text { istekliliğini } \\
\text { belirtmektedir. }\end{array}$ & $\begin{array}{l}\text { lyi huylu, güvenilir, yardımsever, işbirliğinden } \\
\text { yana olan, bağışlayıcı bir kişilik tipidir. Bu } \\
\text { boyutu düşük olan insanlar ise yardımsever } \\
\text { olmayan, inatçı, hemen parlayan diğer insanları } \\
\text { rahatsız eden özellikler sergilerler. }\end{array}$ \\
\hline $\begin{array}{l}\text { Sorumluluk } \\
\text { (Conscientiousness) }\end{array}$ & $\begin{array}{l}\text { Bireyin güvenilirliği } \\
\text { boyutudur. }\end{array}$ & $\begin{array}{l}\text { Bu tür bireyler yaşamlarında sorumlu, bağımlı, } \\
\text { dikkatli, disiplinli kişiliği ifade etmektedir. } \\
\text { Başarıya ulaşma yolunda isteklidir. Bu boyutu } \\
\text { düşük olan bireyler ise dikkatsiz, organize } \\
\text { olmamış, sorumsuz, disiplinsiz özelliklerini } \\
\text { taşımaktadır. }\end{array}$ \\
\hline
\end{tabular}

Kaynak: Özkalp ve Kırel, 2005: 92-93; Can vd., 2006: 77-78.

1980'li yıllarda kişilik özelliklerini belirlemeye yönelik McCrae ve Costa'nın (1987) çalışmalarının ön plana çıktığı görülmektedir. 1985 yılına kadar üç faktörlü (dışadönüklük, nevrotizm ve deneyime açıklık) modeli savunan araştırmacılar yaptıkları çalışmalar sonucunda uyumluk ve sorumluluk boyutlarını keşfederek kişiliğin beş temel boyutu olduğu hipotezini savunmuşlardır (İnanç ve Yerlikaya, 2012: 286). Beş temel kişilik özelliğinin içeriği ve ilişkili sıfatlar yukarıdaki tabloda açıklanmaktadır.

\section{3. Örgüt Kültürü}

Kültür ve yönetim konuları ne kadar birbirinden farklı olarak algılansa da bir toplum içindeki bireylerin sosyal yaşamlarından özel yaşamlarına kadar birçok konuda ilişkili hale gelmektedir (Barlı, 2008: 453). Her bir işletme bir küçük toplum şeklini almakta ve bu toplumun da kendine has "paylaşılan değerler seti" olmaktadır. Bu değerler seti örgütün başarısını ve iç dinamiklerini etkilemekte, küreselleşme ise bu etkiyi daha da artırmaktadır (Koçel, 2005: 31).

Örgüt kültürü konusunun yeni olması (1980 sonrası gelişim göstermesi) ve kültürel yanını oluşturan kısmın sınırlarının belirsiz olması ortak bir tanım yapılmasını zorlaştırmaktadır (Yağmurlu, 1997). Örgüt kültürü; örgüt üyeleri tarafından paylaşılan ve doğru kabul edilen dolaylı varsayımlardır ki bu varsayımlar örgütün nasıl algıladığını, nasıl düşündüğünü ve çevresine nasıl tepki vermesi gerektiğine yön verir (Kreitner ve Kinicki, 2008: 66). Örgüt kültürü, işletme içindeki ve dışındaki insanlara örgüt ile ilişkili inançları, değerleri ve davranışları barındıran mesajların iletilmesini kapsamaktadır (Sweeney ve McFarlin, 2002: 336). Örgüt kültürü, bir işletmenin 
bireyleri tarafından paylaşılan değerleri temsil etmesinin yanı sıra o işletmenin yenilikçi, detaycı, risk alıcı, sonuç odaklı, insan odaklı, rekabetçi, durağan ya da dinamik olmasına etki eden karakteristik özellikleri bünyesinde barındırmaktadır (Robbins ve Judge, 2008: 248).

Allaire ve Firsirotu (1984) örgüt kültürünün yönetim organizasyon literatüründe genelde iki farklı şekilde ele alındığını vurgulamaktadır. Bir görüş kültürü sosyal sistemin parçası olarak ele alırken, diğer görüş ise kavramsal bir ayrıma giderek kültürü bir fikirler sistemi olarak ele almaktadır. Biri kültür ve sosyal yapı arasında ahenk ve uyum konusuna ağırlık verirken, diğeri gözlemlenebilir olayların ardında yatan düşünsel sistemlere göre kültürü yorumlamaktadır. Bir işletmenin sahip olduğu kültür sadece o işletme çalışanlarını, müşterilerini, tedarikçilerini ve rakiplerini belirlemez aynı zamanda bu kilit aktörler ile nasıl etkileşime girileceğini de belirlemektedir (Barney, 1986: 657).

Örgüt kültürü uyulması gereken kurallar ve değerleri belirtmesinin yanı sıra yanlış, gereksiz ve arzu edilmeyeni, izlenmemesi gereken ve başkaları tarafından önerildiği zaman karşı çıkılması gereken hedefler ile eylemleri de öngörmektedir (Can vd., 2006: 428). Örgüt kültürü, örgüt içindeki güçleri birbirine bağlayan, tanımlayan ve güçlendirmeye yardım eden ve pozisyonlardaki rolleri tutan, aşağılara doğru uzanmış, yaygın bir manyetik alan gibi kişinin, grubun ve bütün olarak örgütün verimliliğine etki edebilmektedir (Şimşek, 2002: 336).

İşletmeler pazar, rekabet koşulları ve müşteri beklentilerindeki hızlı değişimlere uyum sağlamak adına yeni örgüt tasarımları ve yönetim yaklaşımları arayışlarına girmişlerdir. Bu aşamada kültür, sosyal alanda ortaya çıkan sorunların çözümünde başvurulacak yeni bir kavramsal çerçeveyi ortaya koymaktadır (Ergün, 2007: 267). Karmaşık bir yapıya sahip örgüt kültürü kavramının daha iyi anlaşılması açısından modellerin faydası göz ardı edilemez. Bu bağlamda birçok araştırmacı (Deal ve Kennedy, 1982; Hofstede 1984; Harrison ve Stokes, 1992; Goffee ve Jones, 1998; Cameron ve Quinn, 1999) örgüt kültürü kavramını farklı yönlerinden ele alarak açıklamaya çalışmıştır. Araştırmada Cameron ve Quinn'in (1999) modelinin baz alınması nedeni ile bu aşamada model detaylıca açıklanacaktır.

Quinn ve Cameron'un ortaya koyduğu "rekabetçi değerler" yaklaşımı yöneticilere örgüt kültürünü anlamaları, ölçmeleri ve değiştirebilmeleri için pratik bir yol sunmaktadır (Kreitner ve Kinicki, 2008). Birbirine zit değerlerin iki temel eksen üzerine oturtulduğu bu modelde, bir eksen işletmenin esnek, değişime açık ya da tam tersi olarak kontrole, istikrara, değişime kapalı olmaya odaklanıp odaklanmadığını değerlendirmektedir. Diğer eksende ise işletmenin öncelikli olarak içsel dinamiklere ve çalışanlarına mı değer verdiğini yoksa dış çevre faktörleri, müşterileri ve paydaşlarına mı değer verdiğine odaklanmaktadır (Greenberg ve Baron, 2008: 549). Quinn ve diğerleri (1991) ortaya konulan modelde değerlerin çatışmasını veya rekabetini şu şekilde dile getirmektedir;

"İşletmemizin uyumlu ve esnek olmasını isteriz ama aynı zamanda kontrol edilebilir ve istikrarlı olmasını da isteriz. İşletmemizin büyümesini, yeni kaynaklar edinmeyi ve dış çevre desteği isterken, sıkı bir bilgi yönetimi ve resmi bir iletişim sistemi de isteriz. İnsan kaynaklarına verilen değer konusuna vurgu yaparken aynı zamanda planlama ve hedef belirleme konularına da vurgu yaparız. Rekabetçi değerler modeli gerçek yaşamdaki zıt değerleri ortaya koymakta, dört farklı örgüt kültürünü birbirinden ayırt etmekle birlikte, bir işletmenin aynı zamanda her birinden bir parça sahibi olabileceğini de bizlere göstermektedir (s.217)." 
İki eksenin bir araya gelmesi ile ortaya çıkan dört farklı kültür türü, her kültürün kendine has itici özelliği, motive edici araçları ve elde ettiği sonuçları şekil 1'de paylaşılmıştır. Bu kültür türlerini detaylıca açıklamak araştırmanın modelinde kullanılması nedeniyle faydalı olacaktır.

\section{Şekil 1: Rekabetçi Değerler Modeli ve Örgüt Tipolojisi}

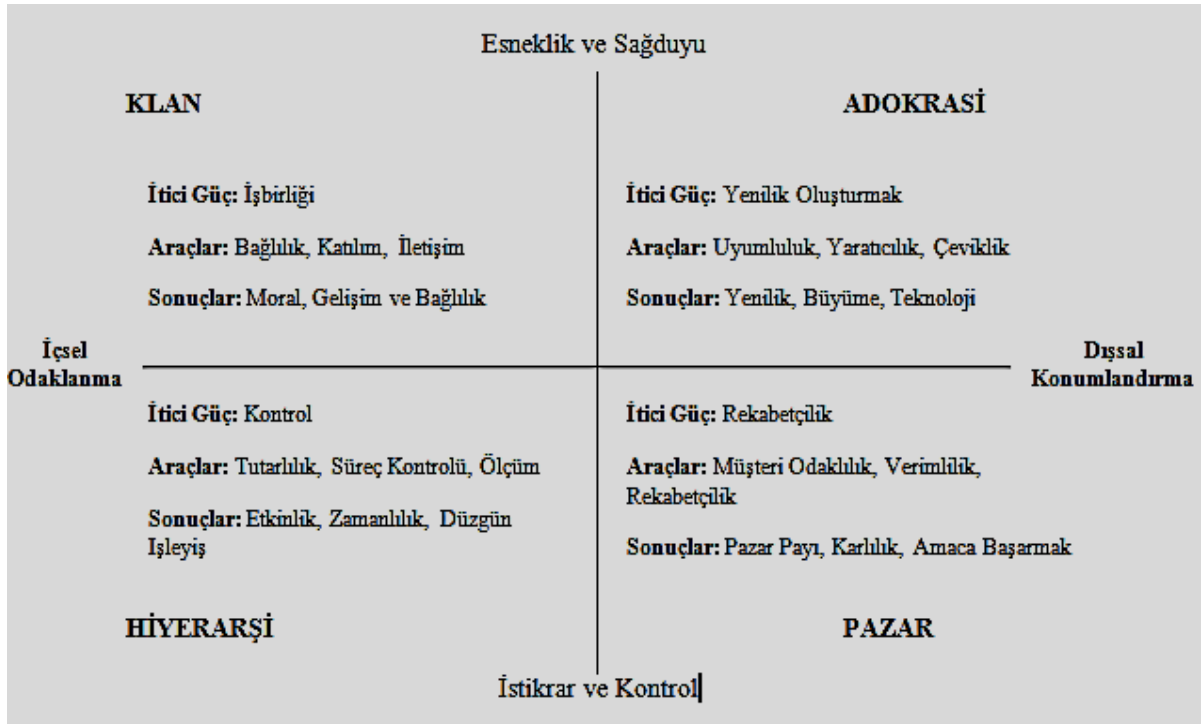

Kaynak: Cameron ve Freeman, 1991: 29.

Hiyerarşi Kültürü: Bu örgüt kültürünün odak noktası içsel organizasyon, temel vurgusu ise istikrardır. İşletme mevcut düzenin ve uygulamaların istikrarlı bir şekilde yürütülmesi amacıyla çalışanlarını güvenlik, emirler, kurallar ve düzenlemeler ile motive etmeye çalışmaktadır. Bu kültürdeki liderler tutucu ve tedbirli olmayı tercih eder, teknik meselelere özel bir ilgi gösterirler. Kültürün işletme içindeki tesiri kontrol mekanizmaları, istikrarın sürdürülmesi ve etkinlik faaliyetleri ile sürdürülemeye çalışılmaktadır (Denison ve Spreitzer, 1991: 6). Ayrıca iş süreçlerinde aksama yaşamamak için ölçümleme, dokümantasyon ve bilgi yönetimine özel ilgi gösterilmektedir (DiPadova ve Faerman, 1993).

Klan Kültürü: Bu kültürde çalışanlar paylaşımın yüksek olduğu, sıcakkanlı insanların bir arada bulunduğu geniş bir aile atmosferi içinde çalışmaktadırlar. Yöneticiler ya da liderler bir danışman, aile reisi figürü şeklinde algılanır. İşletmeye bağlıığın yüksek olduğu, sadakatin ve geleneklerin çalışanları bir arada tuttuğu bir organizasyon yapısı hakimdir. Yüksek düzeyde moral ve bağlılığı sağlayacak uzun dönemli insan kaynakları gelişimine vurgu yapılmaktadır. Başarı, müşterilere karşı duyarlılık ve insan ilişkilerini temel alarak tanımlanmakta, takım çalışmasına, katılımcılığa ve fikir birliğine teşvikler vermektedir (Hoojberg ve Petrock, 1993: 30). Bu tür kültüre sahip bir işletmede lider düşüncelerini çalışanları ile paylaşır, çatışmalı durumlarda fikir birliği sağlanmasına önem verir, uzlaşma yollarını tartışır, çalışanlarının ihtiyaçlarının farkında olup onları dinler ve onlara adil davranmaktadır (Vilkinas ve Cartan, 2006).

Adokrasi Kültürü: Bu kültürde temel vurgu dış çevre koşullarına adaptasyonu sağlamak ve açık bir sistem olarak faaliyet göstermektir. Bu tür organizasyonlardaki liderler esnekliğe, büyümeye, yeniliğe, risk almaya ve kreatifliğe yönelik stratejileri 
destekler ve değer vermektedir (Kalliath vd., 1999: 145). Dinamik, girişimci ve yeniliğe açık bir iş ortamının hüküm sürdüğü bu kültürde insanlar risk almaya teşvik edilir, yeni tecrübeler ve yenilikler insanları bir arada tutar. Bu kültürde başarı eşsiz ve yeni ürün ve hizmetler üretmek ve sektörde liderliği sürdürmektir. Bireysel inisiyatifler ve özgürlük bu işletme türünde teşvik edilmektedir (Dastmalchian vd., 2000).

Pazar (Piyasa) Kültürü: Bu kültüre sahip bir örgüt yüksek verimlilik ve ekonomik işlemler aracılığı ile başarılan rasyonel hedeflere ulaşmaya çalışır. Sonuç odaklı bir örgüt yapısının hüküm sürdüğü bu tür organizasyonlarda çalışanlar rekabete, gayrete, mükemmelliğe, agresifliğe ve bireysel inisiyatiflere değer verir (Igo ve Skitmore, 2006). $\mathrm{Bu}$ kültürde lider işletme performansı ve sonuçlarına odaklanır, kaynak dağılımında öncelikleri belirler ve işin bir an önce bitirilmesine önem verir (Hart ve Quinn, 1993). Ayrıca piyasa odaklı bir anlayışla stratejik analizlere ve stratejik liderlik özelliklerine değer verir (Panayotopoulou vd., 2003).

\subsection{Dini Yönelim}

Din, insanlarda ortak duygu ve inançların gelişmesinde önemli bir toplumsal sistemdir. İnanç ise bireyin dünyasının yönüne ait algı ve bilgilerin devamlı bir organizasyonudur (Barutçugil, 2011: 27). İnsanın dünya-kurma girişiminde stratejik bir rol oynayan, kişinin kendi niteliği ve evrendeki yeri hakkında bütüncül bir bilgi şeması sunan din, özellikle gençlik döneminde benlik kimliğini oluşturma ve dünyayı anlamlandırma açısından önemli işlevler görmektedir (Taş, 2010: 49). Kişinin dindar olup olmadığı ya da dine yönelim düzeyi ancak o kişinin dini tutum ve davranışlarından hareketle tespit edilebilir ki, dini tutumların kişiye özgü içsel ve psikolojik yönü bulunmaktadır (Coştu, 2009: 122). Dini yönelim, insanın dinle ilgili psikolojik yönelimi, onun inanç dünyasıdır. Bireyin dinle ilgili değerlendirme ifade eden her çeşit tepkileri ve bunların derecesi kişinin dini yöneliminin göstergesidir (Kuzgun ve Sevim, 2004: 18).

Allport ve Ross'a (1967) göre dini yönelim dışsal ve içsel olmak üzere iki temel kategoride tanımlanabilir. Dışsal dini yönelimi olan birey güçlü bir gruba üye olma, güvenlik sağlama, kendini doğrulama ve sosyal ilişkiler kurma (Genia ve Shaw, 1991), sosyal statü, korunma ve teselli elde etme veya ego koruma (Kahoe ve Meadov, 1981) amaçlarına hizmet etmek için dine yönelmektedir. Dışsal dini yönelimde birey yönünü Allah'a dönmekte ama kendi benliğinden vazgeçmemektedir (Allport ve Ross, 1967: 434). İçsel dini yönelime sahip bireyler benimsedikleri inancı tam olarak izlemeye çabalar, inancının gereklerini içselleştirmek ve takip etmek için dini başlı başına bir amaç olarak ele alırlar. Ayrıca bu bireyler dini inançlarına bütünüyle bağlı olarak tanımlanır ve dinin etkisi yaşamlarının tüm yönlerinde görülebilmektedir (Allport ve Ross, 1967: 434; Cirhinlioğlu, 2010: 1369-1370). İçsel yönelim daha çok benliğinden uzaklaşmış, inancı gereği Allah'a ve onun koyduğu kurallara yönelen kişileri tanımlarken, dışsal yönelim ben merkezli, faydacı bir anlayışla dini inanca yönelen kişileri tanımlamaya çalışmaktadır. İçsel olarak dindar olanlar kişiler için kişisel inanç önem taşırken, dışsal olarak dindar olan bireyler sosyal bağlamda kazanç yönüne de önem verirler (Cirhinlioğlu, 2006: 20). Hunt ve King (1971) içsel ve dişsal dini yönelim algısının zıt kavramlar olarak algılanmaması gerektiğini belirtmekte, bu ayrımın konunun daha kapsamlı bir şekilde analiz edilmesi için bir adım olarak algılanması gerektiğini belirtmektedir.

\section{Değişkenler Arasındaki İlişkilere Yönelik Çalışmalar}

Etik liderlik ile beş faktör kişilik boyutları arasındaki ilişkiye yönelik literatürün çok sınırlı olduğu görülmektedir. Bu ilişkiyi ortaya koymaya yönelik yapılan sınırlı çalışma 
bulguları kısaca paylaşılmaktadır. Dollinger ve LaMartina (1998) kişilik boyutlarından sorumluluk ile ahlaki muhakeme becerisi arasında pozitif bir yönde ilişki olduğunu belirtmektedir. Sackett ve Wanek (1996) dürüstlük testlerinin kişilik boyutlarından uyumluluk, sorumluluk ve nörotisizm ile ilişkilere sahip olduğunu belirtmektedir. Mayer ve diğerleri (2007) ise çalışmalarında uyumluluk, sorumluluk ve nörotisizm kişilik boyutlarının adil bir örgüt iklimi oluşturmada en önemli liderlik özellikleri olduğunu belirtmektedir. Brown ve Trevino (2006) etik liderlik ile üç kişilik boyutu arasında (uyumluluk, sorumluluk ve nörotisizm) ilişki olabileceğini öne sürerken, dışadönüklük ve deneyime açıklık boyutlarının etik liderlik ile ilişkisi olmayacağını, bu boyutların daha çok karizma ile alakalı boyutlar olduğunu vurgulamaktadır. Walumbwa ve Schaubroeck (2009) çalışmalarında etik liderlik ile kişiliğin uyumluluk ve sorumluluk boyutları arasında olumlu ilişkiler tespit ederken, nörotisizm boyutu ile bir ilişki tespit edilememiştir. Bu bulgular Brown ve Trevino'nun (2006) öne sürdüğü hipotezleri destekler niteliktedir.

Özyer ve Azizoğlu (2010) bireylerin dine bağlılık düzeylerindeki artışın etik tutum gösterme düzeyine de pozitif yönde etki ettiğini belirtmiştir. Ayrıca bir yaratıcı güce inanan kişilerin inanamayanlara kıyasla etik tutumlarının daha belirgin olduğu belirtilmektedir. Kennedy ve Lawton (1998) ise çalışmalarında etik dışı davranmaya istekli olma düzeyi ile dindarlık düzeyleri arasında negatif yönde ve anlamlı ilişkiler tespit etmiştir. Clark ve Dawson'ın (1996) çalışmasına göre dini inanç bireyin kişisel olarak ahlaki karar alma süreçlerinde temel teşkil etmektedir. Wong'un (2008) çalışmasına göre uzun bir süre belirli bir dini inanca sahip olan bireyler, kısa sürelilere kıyasla daha etik davranmaktadır. Ayrıca iş etiği ile dini inanç arasında pozitif yönde bir ilişki olduğunu belirtmektedir.

Etik liderlik konusu ile ilgili yapılan araştırmalar genel olarak değerlendirildiğinde liderin etik olup olmama durumuna odaklanmakta, belirli özellikleri barındırması açısından etik bir lider olarak tanımlanmaktadır. Etik karar verme modellerine baktığımızda ise birçok dışsal değişkenin alınan kararların etik olup olmamasına etkide bulunduğunu belirtilmektedir. Yapılan bu çalışmada etik bir liderin oluşumunda sadece liderin özellikleri değil, dışsal değişkenler olarak içinde bulunduğu örgütün kültürü ve toplumsal kültürün ana unsurlarından biri olarak hayatımıza aktardığımız dini yönelim konuları da birlikte ele alınarak literatüre bütüncül bir yaklaşımla etik liderlik konusu ele alınmıştır.

\section{Araştırmanın Yöntemi}

\subsection{Araştırmanın Evreni ve Örneklemi}

Araştırmanın evrenini Antalya'daki 4 ve 5 yıldızlı otel işletmeleri yöneticileri (Genel Müdür, Müdür Yardımcısı, Departman Müdürleri) oluşturmaktadır. Kültür ve Turizm Bakanlığı Yatııı ve İşletmeler Genel Müdürlüğünden alınan rapora göre 2014 yılında Antalya bölgesinde bulunan 4 ve 5 yıldızlı otel sayısı 405 olarak görülmektedir. Evrenin tamamına ulaşılmaya çalışılmış ancak bu amaca ulaşılamamıştır. Bu nedenle örneklem yoluna gidilmiştir. Öncelikle evreni temsil edecek örneklem sayısını tespit etmek amacıyla " $n=$ N.t2.p.q / d2.(N-1)+t2.p.q" (Yazıcıoğlu ve Erdoğan, 2007, s.70) formülü uygulanmıştır. Araştırmamızdaki hedef kitle sayısı (N) 4050 (her otelde en az 10 yönetici olduğu varsayımıyla), $p=0.5, q=0.5, \alpha=0.05$ için teorik t değeri 1.96 ve örnekleme hatası 0.06 olarak alınmıştır. Alınan değerler formüldeki yerlerine koyulduğunda örneklem sayısı (n) 250 çıkmaktadır. Ulaşılan 312 anketin ortaya çıkan örneklem sayısını temsil edebilecek nitelikte olduğu görülmektedir. Örnekleme yöntemi 
olarak kolayda örnekleme yöntemi seçilmiş ve araştırmaya katılmak isteyen otellere anket çalışması uygulanmıştır.

\subsection{Veri Toplama Tekniği}

Araştırmada veri toplama tekniği olarak anket kullanılmıştır. Anket en genel tanımıyla "cevaplandırıcının daha önce belirlenmiş bir sıralamada ve yapıda oluşturulan sorulara karşılık vermesiyle veri elde etme yöntemi" olarak tanımlanmaktadır (Altunışık vd., 2007: 68). Anket tekniğinin tercih edilme sebebi diğer veri toplama tekniklerine göre farklı bölgelerden çok daha büyük gruplara hızla uygulama olanağının olması ve maliyetinin düşük olmasıdır (Büyüköztürk vd., 2011: 124). Bu bağlamda araştırmamız kapsamında kullanılan örgüt kültürü, kişilik özellikleri, dini yönelim ve etik liderlik ölçeğine ilişkin bilgiler aşağıda paylaşılmaktadır.

Örgüt Kültürü Ölçeği: Deshpande ve diğerlerinin (1993) kullandığı ölçeğin temelleri Cameron ve Freeman'ın (1991) çalışmasına dayanmaktadır. Deshpande ve diğerleri (1993) tarafından geliştirilmiş 16 ifadeli ölçekte örgüt kültürü ile ilgili ifadeler dört boyutta (örgüt türü, örgüt çalışanlarını bir arada tutan bağ, liderlik ve örgütün stratejik vurguları) ele alınmıştır. Dört boyuttaki her bir ifade dört örgüt kültürü tipi (klan, hiyerarşi, adokrasi ve pazar) ile ilişkilidir. Bu ölçekte katılımcıların örgütlerini tanımlamalarına yönelik ifadeler bulunmaktadır. Katılımcılardan her bir ifadeyi okumaları ve genel olarak ifadelerin kendi örgütlerini ne kadar betimlediğini belirtmeleri istenmiştir. Ölçek Erdem (2007) tarafından Türkçeye çevrilmiş, 256 hastane çalışanı üzerinde uygulanmış ve her bir örgüt kültürü boyutunun güvenilirlik katsayıları 0.42 ile 0.82 arasında değiştiği belirtilmiştir. Ölçeğin geçerlilik ve güvenilirlik yapısı Erdem (2007) tarafından ortaya koyulduğu için tekrar değerlendirilmemiştir.

Kişilik Ölçeği: Yapılan değerlendirmeler sonucunda araştırma kapsamında kullanılması en uygun olan kişilik ölçeğinin John ve diğerleri (1991) tarafından geliştirilen beş faktör ölçeği olduğuna karar verilmiştir. Ölçek beş kişilik boyutundan ve 44 ifadeden oluşmaktadır. Ölçek Sümer ve diğerleri (2005) tarafından Türkçeye çevrilmiş ve her bir kişilik boyutunun güvenilirlik katsayılarının 0.64 ile 0.77 arasında değiştiği belirtilmiştir. Ölçeğin geçerlilik ve güvenilirlik yapısı Sümer ve diğerleri (2005) tarafından ortaya koyulduğu için tekrar değerlendirilmemiştir.

Dini Yönelim Ölçeği: Yapılan karşılaştırmalar ve incelemeler sonucunda araştırma desenine en uygun olan Gorsuch ve Venable (1983) tarafından geliştirilen ve Gorsuch ve McPherson (1989) tarafından sadeleştirilen dini yönelim ölçeğinin kullanılmasına karar verilmiştir. Araştırmacılar tarafından Türkçeye çevrilen ölçek uzmanlarla yapılan görüşmeler ve sonrasında yapılan faktör analizi sonucunda 11 ifade ve 2 boyutlu (iç ve dış dini yönelim) bir yapıda temsil edildiği sonucuna ulaşılmıştır. Faktör ve güvenilirlik analizine yönelik bulgular aşağıda paylaşıımaktadır.

Etik Liderlik Ölçeği: Araştırmada kullanılan etik liderlik ölçeği araştırmacılar tarafından geliştirilmiştir. Öncelikle turizm ve otelcilik sektöründe tecrübe sahibi 3 ve örgütsel davranış alanında uzmanlaşmış ve özellikle liderlik alanında araştırmaları bulunan uzman akademisyenlerden 3 kişi ile görüşmeler gerçekleştirilmiştir. Görüşmeler ve literatür taraması doğrultusunda oluşturulan soru havuzunda 568 ifade elde edilmiştir. Alanında uzmanlarla yapılan görüşmeler doğrultusunda anlaşııması zor ve benzeşik yapıya sahip ifadeler gözden geçirilmiş ve 58 ifade geriye kalmıştır. Daha sonrasında gerçekleştirilen pilot çalışma ve analizler sonucunda güvenilirliği düşüren ifadeler çıkarılmış ve 52 ifade ile uygulamaya geçilmiştir. Araştırma kapsamında 
gerçekleştirilen faktör analizi sonucunda etik liderlik ölçeğinin 45 ifade ile tek boyutlu sahip olduğu ortaya konulmuştur.

\subsection{Araştırma Modeli ve Hipotezler}

Araştırma modeli oluşturulurken literatür taramasından elde edilen etik karar alma ve davranış modelleri (Kohlberg ve Hersh, 1977; Rest, 1984; Trevino, 1986; Ferrell ve Gresham, 1985; Jones, 1991; Strong ve Meyer, 1992; Harrington, 1997; Armstrong vd., 2003; Robertson ve Fadıl, 1999); Leonard vd., 2004; Street vd., 2001) ile Seymen ve Bolat'ın (2007) araştırmalarından faydalanıımıştır. Tüm modellerin incelenmesi sonucunda etik bir liderin oluşmasında etki sahibi olabileceği düşünülen değişkenler kişilik, örgüt kültürü ve dini yönelim şeklinde sıralanmış ve değişkenler aşağıdaki şekilde modele yerleştirilmiştir.

\section{Şekil 2: Teorik Araştırma Modeli}

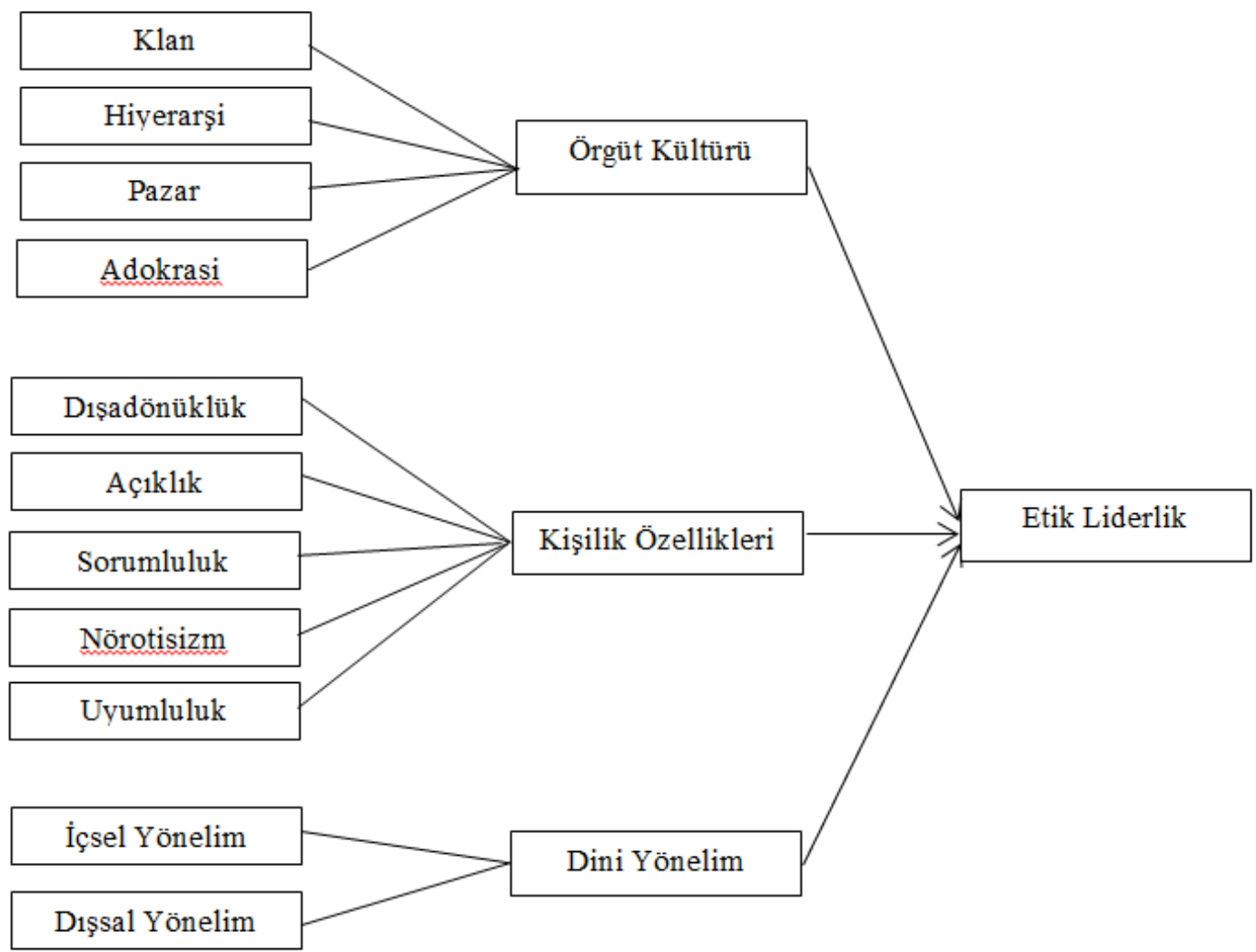

Şekil 2'deki model dikkate alınarak araştırma hipotezleri oluşturulmuştur. Öncelikle örgüt kültürü ile etik liderlik arasındaki ilişkiler kurgulanmıştır. Yöneticinin çalıştığı işletmede yöneticiler ve işletme sahipleri tarafından kurgulanan farklı türdeki örgüt kültürlerinin yöneticinin etik davranışlar sergilemesine etki edeceği öngörülmüştür. Buna bağlı olarak;

H1 $1_{a, b, c, d}$ : Örgüt kültürü boyutları (a)Klan Kültürü, b)Hiyerarşi Kültürü, c)Pazar Kültürü, d)Adokrasi Kültürü) etik liderlik davranışları üzerinde anlamlı bir etkiye sahiptir. 
Örgütsel özelliklerin yanı sıra bireyin kendisini toplumda bir birey olarak nasıl tanımladığına bağlı olarak kişilik özelliklerinin etik liderlik davranışlarına etki edeceği öngörülmüştür. Buna bağlı olarak;

$\mathrm{H} 2_{a, b, c, d, e}$ : Bireyin sahip olduğu kişilik özellikleri (a)Dışadönüklük, b)Açıklık, c)Sorumluluk, d)Nörotisizm, e)Uyumluluk) etik liderlik davranışları üzerinde anlamlı bir etkiye sahiptir.

Bireyin sosyolojik bağlamda kendisine yön veren dini yönelimlerin de etik liderlik davranışlarına etki edeceği öngörülmüştür. Buna bağlı olarak;

$\mathrm{H}_{\mathrm{a}, \mathrm{b}}$ : Bireyin dini yönelimi (a)l̇çsel Dini Yönelim, b)Dışsal Dini Yönelim) etik liderlik davranışları üzerinde anlamlı bir etkiye sahiptir.

\subsection{Araştırmanın Sınırlılıkları}

Araştırmanın en önemli kısıtı yeni bir ölçek geliştirilmesi amacıyla soru havuzunun geniş tutulması sonucunda sektördeki yöneticilerin anketi cevaplandırmaya yanaşmamasıdır. Kapsam ve içerik açısından etik liderlik oluşumuna etki edebilecek birçok değişken varken yalnızca kişilik özellikleri, örgüt kültürü ve dini yönelim algısı değerlendirmeye alınmıştır.

Araştırmada Antalya'da faaliyet gösteren 4 ve 5 yıldızı otel işletme yöneticilerinin değişkenler üzerindeki görüşleri üzerinden etkileşimi ölçülmeye çalışılmış, diğer şehir veya bölgelerdeki otel yöneticilerinin bakış açıları yansıtılmamıştır. Ayrıca sektörel olarak değerlendirildiğinde sadece Antalya bölgesindeki otel işletmeleri kapsama alınmış, sektördeki diğer turizm işletmeleri ya da farklı sektörlerdeki yöneticilerin görüşleri kapsama alınmamıştır. Bu durumlar araştırmanın sınırlılıkları olarak değerlendirilmektedir.

\section{Bulgular}

Hipotezlerin test edilmesi aşamasında karşımıza parametrik ve parametrik olmayan analizler olarak iki seçenek çıkmaktadır. Merkezi limit teoremine göre anakütle dağılımları ne olursa olsun, örnek hacimleri yeteri kadar büyükse $(n \geq 30)$ örnek ortalamaların örnekleme dağılımları normal dağılıma uymaktadır (Lumley vd., 2002:154). Barrett ve Goldsmith (1976) ise örnek hacminin 40'dan büyük olduğu durumlarda örnek ortalamaların örnekleme dağılımlarının normal dağılıma uyacağını belirtmektedir. Buna göre hipotezler parametrik analiz yöntemleri ile test edilmiştir.

$\mathrm{Bu}$ doğrultuda elde edilen veri seti SPSS 21 paket programı aracılığı ile analiz edilmiştir. Bulgular katılımcılar ile ilgili demografik özelliklerin incelendiği betimsel analizler, sonrasında araştırma modelini oluşturan değişkenlerle ilgili açımlayıcı faktör analizleri ve çoklu doğrusal regresyon analizleri aracılığı ile ortaya konulacaktır.

\subsection{Demografik Bulgular}

Elde edilen demografik bilgiler ışığında özet olarak katılımcıların önemli bir kısmının erkek (\%72) katılımcılardan oluştuğu ve yarısından fazlasının (\%55) evli olduğu ortaya çıkmıştır. Katılımcıların büyük bir kısmının yetişme dönemini aile yanında (\%93) geçirdiği, gerek anne (\%70) gerek babalarının (\%57) eğitim düzeylerinin düşük olduğu (okur yazar değil ya da ilköğretim) tespit edilmiştir. Katılımcıların orta düzeyde (2000 TL) aylık gelire sahip olduğu (\%42), çalışma süreleri ele alındığında önemli bir çoğunluğun turizm sektöründe uzmanlaşmış kişiler (16 yıl ve üzeri) olduğu (\%34), günlük çalışma süresi bakımından önemli bir çoğunluğun (\%46) 9 saat üzeri çalıştığı 
görülmektedir. Bununla birlikte birçok yöneticinin kendi otellerinde etik kodların var olduğunu (\%49) belirtmesi ilgi çekici demografik bulgulardır.

\subsection{Faktör Analizi Bulguları}

Yapı geçerliliğini incelemede amaç, ölçeğin faktör yapısını ortaya çıkarmak ise "açımlayıcı faktör analizi"; amaç, daha önce belirlenen ölçek faktör yapısının belirlenmesi ise "doğrulayıcı faktör analizi", teknikleri kullanılır (Büyüköztürk vd., 2011: 121).

Albayrak (2006) KMO testinde 0.70 ile 0.80 arası değerlerin faktör analizi için iyi olduğunu belirtmektedir. Katıımcıların etik liderlik davranışlarına bakış açılarını değerlendirmeye yönelik ortaya konulan 52 önermenin KMO değerinin 0,928 gibi bir değerle faktör analizine uygun olduğu görülmektedir. Bartlett testi sonucuna göre ise (Sig. $=0,00 ; p<0,05)$ değişkenler arasında yüksek korelasyon olduğu sonucuna ulaşıımıştır. İlk yapılan faktör analizi sonucunda 11 faktör yapısı ortaya çıkmıştır. Birinci faktörün özdeğer skoru 21.158 ve açıkladığı varyans oranı \%41 iken ikinci faktör 2.199'luk özdeğer skoruna sahip olmakla varyans açıklama oranı \%6 da kalmakta ve diğer oluşan faktörler daha düşük düzeylerde skorlara sahiptir. Bu sonuç ölçeğin tek boyutlu olma intimalini güçlendirmiş ve incelenen scree plot grafiği sonucunda ölçeğin tek boyutlu olarak daha sağlam bir yapıda temsil edilebileceğine karar verilmiştir.

Tekrarlanan faktör analizleri sonucunda ölçeğin tek boyutlu yapıdaki skorları aşağıdaki tabloda paylaşılmaktadır.

Tablo 3: Etik Liderlik Ölçeği Faktör Analizi Bulguları

\begin{tabular}{|l|c|c|c|c|c|c|}
\hline \multirow{2}{*}{ Faktörler } & \multicolumn{3}{|c|}{ Önceki Özdeğerler } & \multicolumn{3}{c|}{ Sonraki Özdeğerler } \\
\cline { 2 - 7 } & Toplam & \%Varyans & \%Kümülatif & Toplam & \%Varyans & \%Kümülatif \\
\hline 1 & 20.783 & 46.186 & 46.186 & 20.783 & 46.186 & 46.186 \\
\hline 2 & 2.369 & 5.265 & 51.451 & & & \\
\hline 3 & 1.647 & 3.659 & 55.110 & & & \\
\hline 4 & 1.418 & 3.150 & 58.260 & & & \\
\hline
\end{tabular}

Açıklanan varyans oranına bakıldığında tek faktörün toplam varyansı açıklama oranının yükselerek \%46’ya ulaştığı görülmektedir. Büyüköztürk (2010) tek faktörlü ölçeklerde açıklanan varyansın \%30 ve daha fazla olmasının yeterli görülebileceğini belirtmektedir. Buna göre analiz sonucunda elde edilen tek faktör ve bu tek faktörün toplam varyansı açıklama oranı yeterli olarak görülmüştür. Gerçekleştirilen faktör analizi sonucunda elde edilen bileşen matrisinde bulunan faktör yüklerinin 0.81 ile 0.46 arasında değiştiği tespit edilmiştir. Tabachnick ve Fidell (2007) temel bir kural olarak her bir değişken yük değerinin 0.32 ve daha üzerinde değerlendirilmesi gerektiğini belirtmiş̧tir. Bu veriye dayanarak faktör yüklerinin yeterli düzeyde olduğu söylenebilir. Katılımcıların dini yönelime bakış açılarını değerlendirmeye yönelik ortaya konulan 11 önermenin KMO değerinin 0,855 gibi bir değerle faktör analizine uygun olduğu görülmektedir. Bartlett testi sonucuna göre ise (Sig. $=0,00 ; p<0,05$ ) değişkenler arasında yüksek korelasyon olduğu sonucuna ulaşılmıştır. Birinci faktör toplam varyansın \%40.2'sini ve ikinci faktör \%15.3'ünü açıklamaktadır. Faktörlerin ayrı ayrı varyansa yaptıkları katkılara bakıldığında; ikinci faktörden sonra katkının azaldığı görülmektedir. Özdeğerler değerlendirildiğinde $(4.424,1.690) 11$ önermenin iki faktör altında toplandığı görülmektedir. 
Tablo 4: Dini Yönelim Ölçeği Faktör Analizi Bulguları

\begin{tabular}{|l|c|c|c|c|c|c|}
\hline \multirow{2}{*}{ Faktörler } & \multicolumn{3}{|c|}{ Önceki Özdeğerler } & \multicolumn{3}{c|}{ Sonraki Özdeğerler } \\
\cline { 2 - 7 } & Toplam & \%Varyans & \%Kümülatif & Toplam & \%Varyans & \%Kümülatif \\
\hline 1 & 4.424 & 40.219 & 40.219 & 4.382 & 39.839 & 39.839 \\
\hline 2 & 1.690 & 15.360 & 55.579 & 1.731 & 15.740 & 55.579 \\
\hline 3 & 0.947 & 8.608 & 64.188 & & & \\
\hline 4 & 0.866 & 7.877 & 72.065 & & & \\
\hline
\end{tabular}

Açıklanan varyans oranına bakıldığında iki faktörün toplam varyansı açıklama oranının \%55 olduğu görülmektedir. Büyüköztürk (2010) çok faktöre sahip ölçeklerde açıklanan varyansın $\% 30$ ve daha fazla olmasının yeterli görülebileceğini belirtmektedir. Buna göre analiz sonucunda elde edilen iki faktör ve bu iki faktörün toplam varyansı açıklama oranı yeterli olarak görülmüştür. Yapılan faktör analizi sonucunda elde edilen bileşen matrisinde bulunan faktör yükleri incelendiğinde birinci boyut altındaki faktör yüklerinin 0.80 ile 0.61 arasında, ikinci boyut altındaki faktör yüklerinin ise 0.82 ile 0.56 arasında değiştiği tespit edilmiştir.

\subsection{Betimleyici İstatistikler}

Gerçekleştirilen faktör analizlerinden sonra, elde edilen değişkenlerle ilgili betimleyici istatistikler değerlendirilmiştir. Her bir değişkene ait ortalama, standart sapma, güvenilirlik katsayıları, soru sayıları ve kullanılan ölçek düzeyleri ile ilgili sonuçlar tablo 5'de sunulmaktadır.

Tablo 5: Değişkenler İle İlgili Tanımlayıcı İstatistikler

\begin{tabular}{|c|c|c|c|c|c|}
\hline Yapılar & Ortalama & $\begin{array}{c}\text { Standart } \\
\text { Sapma }\end{array}$ & $\begin{array}{c}\text { Soru } \\
\text { Sayısı }\end{array}$ & $\begin{array}{c}\text { Güvenilirlik } \\
\text { Katsayısı }\end{array}$ & $\begin{array}{c}\text { Ölçek } \\
\text { Düzeyi }\end{array}$ \\
\hline Etik Liderlik & 4,31 & 0,50 & 45 & .97 & 5 \\
\hline Sorumluluk & 3,90 & 0,58 & 9 & .74 & 5 \\
\hline Uyumluluk & 3,90 & 0,56 & 9 & .70 & 5 \\
\hline Dışadönüklük & 3,78 & 0,57 & 8 & .68 & 5 \\
\hline Açıklık & 3,85 & 0,50 & 10 & .68 & 5 \\
\hline Nörotisizm & 2,75 & 0,54 & 8 & .52 & 5 \\
\hline Klan Kültürü & 3,87 & 0,78 & 4 & .77 & 5 \\
\hline Adokrasi Kültürü & 3,81 & 0,71 & 4 & .72 & 5 \\
\hline Pazar Kültürü & 3,72 & 0,71 & 4 & .71 & 5 \\
\hline Hiyerarşi Kültürü & 3,89 & 0,71 & 4 & .64 & 5 \\
\hline Içsel Dini Yönelim & 3,36 & 0,69 & 8 & .87 & 5 \\
\hline Dışsal Dini Yönelim & 3,81 & 0,87 & 3 & .55 & 5 \\
\hline
\end{tabular}

Değişkenlere yönelik tanımlayıcı istatistikler incelendiğinde katılımcıların yüksek düzeyde kendilerini etik davranışlar sergileyen bir lider olarak gördükleri söylenebilir. Bununla birlikte katılımcılar kişilik özellikleri bakımından kendilerini uyumlu, sorumlu, dışadönük ve açık bireyler olarak tanımlarken nörotisizm olarak adlandırılan duygusal denge durumlarına yönelik skor düşük düzeydedir. Araştırmaya katılan otel işletmelerinde tüm kültür yapıları bulunmakla birlikte baskın olarak klan ve hiyerarşi kültürleri ön plana çıkmaktadır. Dini yönelim açısından ise katılımcılar kendilerini daha çok dış dini yönelimli bireyler olarak tanımlamıştır. Alfa katsayısı için kabul edilebilir bir değerin en az 0.70 olması arzu edilir. Ancak inceleme türü çalışmalarda bu değerin 0.50'e kadar makul kabul edilebileceği de bazı araştırmacılarca öngörülmektedir (Altunışık, 2007, s.116). Buna göre .52 ile .97 arasında değişen katsayıların güvenilir düzeyde olduğu söylenebilir. 


\subsection{Regresyon Analizi Bulguları}

Bu kısımda araştırmanın değişkenleri arasındaki etkileşimleri belirlemeye ve hipotezleri test etmeye yönelik çoklu regresyon analizi bulguları paylaşılmaktadır. Regresyon analizi yapabilmek için gerekli koşullardan biri olan normal dağılım şartının sağlandığını bulgular kısmının başında belirtmiştik. Bununla beraber otokorelasyonu test etmek amacıyla elde edilen Durbin Watson değerleri ise 1.5 ile 2.5 arasında olduğu görülmüştür. Bu aralıkta bulunan değerler ise regresyon analizinin diğer bir varsayımı olan otokorelasyonun olmadığını ortaya koymaktadır (Küçüksille, 2010).

Tablo 6: Örgüt Kültürü Tipleri ile Etik Liderlik Davranışı Arasındaki Regresyon Analizi Bulguları

\begin{tabular}{|c|c|c|}
\hline Bağımsız Değişkenler & Beta & $\begin{array}{c}\text { t Değerinin Anlamlılık } \\
\text { Düzeyi }\end{array}$ \\
\hline Klan & 0.149 & 0.000 \\
\hline Pazar & 0.118 & 0.119 \\
\hline Hiyerarşi & 0.120 & 0.150 \\
\hline Adokrasi & 0.026 & 0.775 \\
\hline $\mathbf{R}^{2}$ & $\mathbf{F}$ & $\begin{array}{c}\text { F Değerinin Anlamlılık } \\
\text { Düzeyi }\end{array}$ \\
\hline 0.046 & 13.019 & 0.000 \\
\hline
\end{tabular}

Tablodaki bulgulara göre bağımsız değişkenlerin bağımlı değişkeni açıklama düzeyi istatistiki açıdan anlamlıdır $\left(R^{2}=0.046, F=13.019, p=0.000\right)$. Bağımsız değişken olarak örgüt kültür tiplerinden klan kültürünün $(\beta=0.149, p=0.000)$ bağımlı değişken olan etik liderlik davranışlarını açıklama düzeyi istatistiksel olarak anlamlı bulunmuştur. Söz konusu bağımsız değişkenin bağımlı değişken olan etik liderlik davranışları üzerinde $\% 5$ gibi bir etkiye sahip olduğu bulunmuştur. Buna göre $\mathrm{H} 1_{\mathrm{a}}$ hipotezi kabul edilmiş, $\mathrm{H} 1_{\mathrm{b}}, \mathrm{H} 1_{\mathrm{c}}$ ve $\mathrm{H} 1_{\mathrm{d}}$ hipotezleri reddedilmiştir.

Tablo 7: Kişilik Özellikleri ile Etik Liderlik Davranışı Arasındaki Regresyon Analizi Bulguları

\begin{tabular}{|c|c|c|}
\hline Bağımsız Değişkenler & Beta & $\begin{array}{c}\text { t Değerinin Anlamlılık } \\
\text { Düzeyi }\end{array}$ \\
\hline Uyumluluk & 0.338 & 0.000 \\
\hline Açıklık & 0.281 & 0.000 \\
\hline Sorumluluk & 0.082 & 0.246 \\
\hline Dışadönüklük & 0.025 & 0.713 \\
\hline Nörotisizm & 0.019 & 0.746 \\
\hline $\mathbf{R}^{2}$ & $\mathbf{F}$ & $\begin{array}{c}\text { F Değerinin Anlamlılık } \\
\text { Düzeyi }\end{array}$ \\
\hline 0.274 & 47.319 & 0.000 \\
\hline
\end{tabular}

Tablodaki bulgulara göre bağımsı değişkenlerin bağımlı değişkeni açıklama düzeyi istatistiki açıdan anlamlıdır $\left(R^{2}=0.274, \quad F=47.319, p=0.000\right)$. Bağımsız değişken olarak kişilik özelliklerinden uyumluluk $(\beta 1=0.338, p=0.000)$ ve açıklığın $(\beta 2=0.281, p=0.000)$ bağımlı değişken olan etik liderlik davranışlarını açıklama düzeyi istatistiksel olarak anlamlı bulunmuştur. Söz konusu bağımsız değişkenlerin bağımlı değişken olan etik liderlik davranışları üzerinde \%27 gibi bir etkiye sahip olduğu bulunmuştur. Buna göre $\mathrm{H} 2_{b}$ ve $\mathrm{H} 2_{e}$ hipotezleri kabul edilmiş, $\mathrm{H} 2_{a}, H 2_{c}$ ve $\mathrm{H} 2_{d}$ hipotezleri reddedilmiştir. 


\section{Tablo 8: Dini Yönelim ile Etik Liderlik Davranışı Arasındaki Regresyon Analizi Bulguları}

\begin{tabular}{|c|c|c|}
\hline Bağımsız Değişkenler & Beta & $\begin{array}{c}\text { t Değerinin Anlamlılık } \\
\text { Düzeyi }\end{array}$ \\
\hline İçsel Dini Yönelim & 0.184 & 0.000 \\
\hline Dışsal Dini Yönelim & -0.122 & 0.000 \\
\hline $\mathbf{R}^{2}$ & $\mathbf{F}$ & $\begin{array}{c}\text { F Değerinin Anlamlılık } \\
\text { Düzeyi }\end{array}$ \\
\hline 0.107 & 15.507 & 0.000 \\
\hline
\end{tabular}

Tablodaki bulgulara göre bağımsız değişkenlerin bağımlı değişkeni açıklama düzeyi istatistiki açıdan anlamlıdır $\left(R^{2}=0.107, F=15.507, p=0.000\right)$. Bağımsız değişken olarak içsel dini yönelim $(\beta 1=0.184, p=0.000)$ ve dişsal dini yönelim $(\beta 2=-$ $0.122, p=0.000$ ) bağımlı değişken olan etik liderlik davranışlarını açıklama düzeyi istatistiksel olarak anlamlı bulunmuştur. Söz konusu bağımsız değişkenlerin bağımlı değişken olan etik liderlik davranışları üzerinde \%11 gibi bir etkiye sahip olduğu bulunmuştur. Buna göre $\mathrm{H}_{3}$ ve $\mathrm{H}_{\mathrm{b}}$ hipotezleri kabul edilmiştir.

\section{Sonuçlar}

Sosyal bilimler alanında gün geçtikçe önem kazanan ve araştırma kapsamı genişleyen konulardan biride liderlik konusudur. Yapılan çalışmalar genellikle liderliğin yapıcı, etkili ve başarılı (Uğurluoğlu ve Çelik, 2009; Bakan ve Doğan, 2012; Marques, 2010; Amabile vd., 2004; De Hoogh vd., 2005) yönlerini ele alırken yakın zamanda büyük şirketlerdeki etik skandallar araştırmacıları liderliğin yıkıcı, suistimal edici ve negatif etki meydana getirici (Hoobler ve Hu, 2013; Martinko vd., 2011; Schyns ve Schilling, 2013; Schaubroeck vd., 2007) yönlerini de ele alan araştırmalar yapmaya yönelttiği görülmektedir. Liderlik yaklaşımlarının gelişim süreci dahilinde son yaklaşım olan ve yeni liderlik türleri içinde değerlendirilen etik liderlik yaklaşımı, liderliğin olumsuz yanlarını bertaraf ederek, gerek çalışanlara, gerek müşterilere gerekse paydaşlara yönelik etik bir yaklaşımı savunmaktadır. Ayrıca etik liderlik yaklaşımı karar alma süreçlerinde bireysel faydacılığın ötesinde toplumsal faydayı da gözeten bir süreci savunmaktadır. Araştırma kapsamında intiyaç duyulan etik bir liderin oluşumunda etki sahibi faktörlerin neler olabileceği sorusuna cevap aranmıştır.

Yapılan regresyon analizleri sonucunda etik liderlik eğilimini açıklamaya yönelik ortaya koyulan değişkenlerden en önemli yordayıcının kişilik özellikleri olduğu görülmektedir. Yapılan analiz sonucunda kişilik özelliklerinden uyumluluk ve açıklık değişkenlerinin etik liderlik değişkenindeki varyasyonun \%27'sini açıklayabildiği tespit edilmiştir. Kişilik özelliklerinden uyumluluk bireyin diğerleri ile uyum içinde olmasındaki istekliliğini belirtirken açıklık bireylerin ilgilerinin genişliğini ve yeniliklerden büyülenme derecesini belirtmektedir (Özkalp ve Kırel, 2005). Analiz sonucunda tespit edilen uyumluluk özelliğinin etik liderin oluşmasında etki sahibi olduğu yönündeki bulgumuz Shih ve diğerleri (2009), Judge ve diğerleri (2002), Judge ve Bono (2000), Sackett ve Wanek (1996), Mayer ve diğerleri (2007), Brown ve Trevino (2006), Walumbwa ve Schaubroeck (2009), Kalshoven ve diğerlerine (2011) ait çalışmalar tarafından desteklenmektedir. Açıklık boyutunun sahip olduğu etki Strang ve Kuhnert (2009) tarafından desteklenmekte ancak yukarıda belirtilen çalışmalar bir ilişki olmadığın sonucunu desteklemektedir. Liderlerin uyumlu, yardımsever ve işbirlikçi özellikler sergilemesi, yeni tecrübelere ve fikirlere açık olması, meraklı bir şekilde öğrenmeye meyilli olması, kreatif faaliyetlere destek vermesi ve gerektiği zaman esnek davranması kendisinin bir rol model olarak algılanmasında destek verici özellikler olduğunu belirtebiliriz. Uyumlu ve yeniliklere açık bir lider gerek karar alma süreçlerinde ve karşılaşılan olaylar sonucu ortaya konan davranışlarında, gerek hitap edilen kesimler 
ile iletişiminde kendisini kabul ettirmesinde ve bu süreçleri etik bir anlayışla yürütmesinde destek sahibi özellikler olduğu söylenebilir.

Analiz sonucunda örgüt kültürü tiplerinden sadece klan kültürünün etik liderlik değişkenindeki varyasyonun \%5'ini açıklayabildiği tespit edilmiştir. Klan kültürü kardeşçe ilişkilerin olduğu, karşılıklı olarak uzun süreçli bağlıl̆ın ve çıkarların bulunduğu, bireylerin o örgütte bulunmaktan gurur duyduğu, dayanışmanın ön planda olduğu, bireysellikten çok kolektifliğe vurgunun yapıldığı, liderlerin rol model olarak mentorluk yaptığı örgüt tipidir (Kerr ve Slocum, 1987). Bu tür kültüre sahip bir işletmede lider düşüncelerini çalışanları ile paylaşır, çatışmalı durumlarda fikir birliği sağlanmasına önem verir, uzlaşma yollarını tartışır, çalışanlarının ihtiyaçlarının farkında olup onları dinler ve onlara adil davranır (Vilkinas ve Cartan, 2006). Liderin işletme içinde takındığı tavırlar ve sergilediği tutumlar ile bir rol model olarak elindeki gücü etik davranış kalıplarını benimsetme yönünde kullanması örgüt kültürünü güçlendirmektedir (Butts, 2008). Etik davranış sergileyen liderler içinde etik uygulamaların önemli bir yer tutuğu kendi örgüt kültürlerini geliştirebilmektedir (Huhtala vd., 2013). Klan kültürünün sahip olduğu bu özellikler doğrultusunda etik bir liderin ortaya çıkmasında etkin bir role sahip olduğu söylenebilir.

Yapılan regresyon analizi sonucunda dini yönelim türlerinden içsel ve dışsal dini yönelim değişkenlerinin etik liderlik değişkenindeki varyasyonun \%10'unu açıklayabildiği tespit edilmiştir. Yapılan analiz sonucunda dini hayatlarının temeline koyan ve bir yaşam biçimi olarak ele alan bireylerin etik liderlik davranışlarını açıklamada önemli bir etkiye sahip olduğu, dışsal dini yönelime sahip bireylerin ise daha çok kendi benliğini ön planda tutması nedeniyle etik liderliği negatif yönde etkileyen bir değişken olduğu sonucu ortaya çıkmaktadır. Turizm sektörü sahip olduğu yapısı gereği uzun iş saatleri, yoğun iş temposu, etkileşimde bulunulan insanların çeşitliliği gibi özellikleri nedeni ile bireylerin dini yönelimlerini tam anlamıyla ifade edemediği bir sektör olarak karşımıza çıkmaktadır. Bu noktada hiç olmazsa içsel dini yönelimi olan bireylerin benmerkezcilikten uzak ve yaptığı her fiilin hesabının sorulacağına yönelik inancı bu bireyleri etik tutum ve davranışların uygulanmasına daha yatkın hale getirdiğini bilmek gerekmektedir. Dışsal dini yönelime sahip bireylerin ise inançlı bireyler olmaları ile birlikte daha çok benmerkezci ve bireysel faydayı göz önünde bulunduran bir yapıda olmaları, bu tür bireylerin etik liderlik sergilemelerini engellemektedir.

\section{Kaynakça}

Albayrak, A.S. (2006), Uygulamalı Çok Değişkenli Istatistik Teknikleri, Ankara: Asil Yayın Dağıtım.

Allaire, Y. ve Firsirotu, M.E. (1984), "Theories of Organizational Culture", Organization Studies, 5(3), ss.193-226.

Allport, G.W. ve Odbert, H.S. (1936), "Trait-Names: A Psycho-lexical Study", Psychological Monographs, 47(1), ss.1-178.

Allport, G.W. ve Ross, J.M. (1967), "Personal Religious Orientation and Prejudice", Journal of Personality and Social Psychology, 5(4), ss.432-443.

Altunışık, R., Coşkun, R., Bayraktaroğlu, S., Yıldırım, E. (2007), Sosyal Bilimlerde Araştırma Yöntemleri-SPSS Uygulamalı, 5. Baskı, Sakarya: Sakarya Yayıncılık.

Amabile, T.M., Schatzel, E.A., Moneta, G.B. ve Kramer, S.J. (2004), "Leader Behaviors and the Work Environment for Creativity: Perceived Leader Support", The Leadership Quarterly, 15(1), ss.5-32.

Armstrong, M.B., Ketz, J.E., ve Owsen, D. (2003), "Ethics Education in Accounting: Moving Toward Ethical Motivation and Ethical Behavior", Journal of Accounting Education, 21(1), ss.1-16. 
Atkinson, R.L., Atkinson, R.C., Smith, E.E., Bem, D.J. ve Nolen-Hoeksema, S. (2010), Hilgard's Introduction to Psychology (Psikolojiye Giriş), 12th Edition (6. Baskı), Çev. Yavuz Alogan, Ankara: Arkadaş Yayınevi.

Avolio, B.J., Walumbwa, F. ve Weber, T.J. (2009), "Leadership: Current Theories, Research and Future Directions", Annual Review of Psychology, 60, ss.421-449.

Bakan, İ. ve Doğan, İ.F. (2012), "Hizmetkar Liderlik", Kahramanmaraş Sütçü İmam Üniversitesi IiBF Dergisi, 2(2), ss.1-12.

Barlı, Ö. (2008), Davranış Bilimleri ve Örgütlerde Davranış, 3.Baskı, Erzurum: Aktif Yayınevi.

Barney, J.B. (1986), "Can It Be a Source of Sustained Competitive Advantage?", The Academy of Management Review, 11(3), ss.656-665.

Barrett, J.P. ve Goldsmith, L. (1976), "When is n Sufficiently Large?", The American Statistician, 30(2), ss.67-70.

Barutçugil, İ. (2011), Kültürler Arası Farklııkların Yönetimi, İstanbul: Kariyer Yayıncılık.

Brown, M.E., Treviño, L.K. ve Harrison, D.A. (2005), "Ethical Leadership: A Social Learning Perspective for Construct Development and Testing", Organizational Behavior and Human Decision Processes, Vol. 97, ss.117-134.

Brown, M.E. ve Treviño, L.K. (2006), "Ethical Leadership: A Review and Future Directions", The Leadership Quarterly, Vol. 17, ss.95-616.

Butts, J.B. (2008), "Ethics in Organisations and Leadership", Jones And Bartlett Publishers [online], ss.119-151.

Büyüköztürk, Ş., Kılıç Çakmak, E., Akgün, Ö.E., Karadeniz, Ş. ve Demirel, F. (2011), Bilimsel Araştırma Yöntemleri, 9. Baskı, Ankara: Pegem Akademi Yayınları.

Büyüköztürk, Ş. (2010), Sosyal Bilimler İçin Veri Analizi El Kitabı, 11. Baskı, Ankara: Pegem Akademi Yayınları.

Cameron, K.S. ve Quinn, R.E. (1999), Diagnosing and Changing Organizational Culture: Based on the Competing Values Framework, Addison-Wesley.

Cameron, K.S. ve Freeman, S.J. (1991), "Cultural Congruence, Strength and Type: Relationships to Effectiveness", Research in Organizational Change and Development, Vol.5, ss.23-58.

Can, H., Aşan Ö. ve Aydın, E.M. (2006), Örgütsel Davranış, İstanbul: Arıkan Yayıncılık.

Cattell, R.B. (1945), "The Description of Personality: Principles and Findings in a Factor Analysis", The American Journal of Psychology, 58(1), ss.69-90.

Cattell, R.B. (1947), "Confirmation and Clarification of Primary Personality Factors", Psychometrika, 12(3), ss.197-220.

Cirhinlioğlu, F.G. (2010), "Dini Yönelimler ve Önyargı", Uluslararası Ínsan Bilimleri Dergisi, 7(1), ss.1366-1384.

Cirhinlioğlu, F.G. (2006), Üniversite Öğrencilerinde Utanç Eğilimi, Dini Yönelimler, Benlik Kurguları ve Psikolojik İyilik Hali Arasındaki İlişkiler, Doktora Tezi, Hacettepe Üniversitesi Sosyal Bilimler Enstitüsü, Ankara.

Clark, J.W. ve Dawson, L.E. (1996), "Personal Religiousness and Ethical Judgements: An Empirical Analysis", Journal of Business Ethics, 15, ss.359-372.

Costa, P.T. ve McCrae, R.R. (1992), "Four Ways Five Factors are Basic", Personality and Individual Differences, 13(6), ss.653-665.

Coştu, Y. (2009), "Dine Normatif ve Popüler Yaklaşım: Bir Dini Yönelim Ölçeği Denemesi", Hitit Üniversitesi Illahiyat Fakültesi Dergisi, 8(15), ss.119-139.

Dastmalchian, A., Lee, S. ve Ng, I. (2000), "The Interplay Between Organizational and National Cultures: A Comparison of Organizational Practices in Canada and South Korea Using the Competing Values Framework", Int. J. of Human Resource Management, 11(2), ss.388-412.

De Hoogh, A.H.B., Den Hartog, D.N., Koopman, P.L., Thierry, H., Van Den Berg, P.T., Van Der Weide, J.G. ve Wilderom, C.P.M. (2005), "Leader Motives, Charismatic 
Leadership, and Subordinates' Work Attitude in the Profit and Voluntary Sector", The Leadership Quarterly, 16(1), ss.17-38.

Deal, T.B. ve Kennedy, A. (1982). Corporate Culture: The Rites and Rituals of Corporate Life, Addison-Wesley.

Denison, D.R. ve Spreitzer, G.M. (1991), "Organizational Culture and Organizational Development: A Competing Values Approach", Research in Organizational Change and Development, Vol.5, ss.1-21.

Deshpande, R., Farley, J.U. ve Webster Jr., F.E. (1993), "Corporate Culture, Customer Orientation, and Innovativeness in Japanese Firms: A Quadrad Analysis", Journal of Marketing, Vol.57, ss.23-27.

Digman, J.M. (1989), "Five Robust Trait Dimensions: Development, Stability and Utility", Journal of Personality, 57(2), ss.195-214.

Digman, J.M. (1990), "Personality Structure: Emergence of the Five-Factor Model", Annual Review of Psychology, Vol.41, ss.417-440.

DiPadova, L.N. ve Faerman, S.R. (1993), "Using the Competing Values Framework to Facilitate Managerial Understanding Across Levels of Organizational Hierarchy", Human Resource Management, 32(1), ss.143-174.

Dollinger, S.J., ve LaMartina, A.K. (1998), "A Note on Moral Reasoning and the FiveFactor Model", Journal of Social Behavior and Personality, 13, ss.349-358.

Dönmezer, S. (1982), Sosyoloji, 8. Basım, Ankara: Savaş Yayınları.

Eisenbeiss, S.A. (2012), "Re-Thinking Ethical Leadership: an Interdisciplinary Integrative Approach", The Leadership Quarterly, Vol.23, ss.791-808.

Erdem, R. (2007), "Örgüt Kültürü Tipleri ile Örgütsel Bağlılık Arasındaki İlişki: Elazığ İı Merkezindeki Hastaneler Üzerinde Bir Çalışma", Eskişehir Osmangazi Üniversitesi IiBF Dergisi, 2(2), ss.63-79.

Ergün, E. (2007), “Kurum Kültürünü Analiz Etmede Quinn ve Cameron'un Rekabetçi Değerler Analizi", 15. Yönetim ve Organizasyon Kongresi, ss.266-271.

Erkal, B. (2009), "Kişilik Psikolojisi ve Kişilik Kuramları" içinde E. Özalp (Ed.), Davranış Bilimlerine Giriş, Eskişehir: Anadolu Üniversitesi Yayınları.

Ferrell, O.C. ve Gresham, L.G. (1985), “A Contingency Framework for Understanding Ethical Decision Making in Marketing", Journal of Marketing, 49(3), ss.87-96.

Genia, V. ve Shaw, D.G. (1991), "Religion, Intrinsic-Extrinsic Orientation, and Depression", Review of Religious Research, 32(3), ss.274-283.

GH (Gelişim Hachette). (1983), Alfabetik Genel Kültür Ansiklopedisi, Cilt.6, İstanbul: Gelişim Yayınları.

Goffee, R. ve Jones, G. (1998). The Character of a Corporation: How Your Company's Culture Can Make or Brake Your Business, New York: Harper Business.

Goldberg, L.R. (1990), "An Alternative "Description of Personality": The Big-Five Factor Structure", Journal of Personality and Social Psychologs, 59(6), ss.1216-1229.

Goldberg, L.R. (1992), "The Development of Markers for the Big-Five Factor Structure”, Psychological Assessment, 4(1), ss.26-42.

Gorsuch, R.L. ve McPherson, S.E. (1989), "Intrinsic/Extrinsic Measurement: I/ERevised and Single-Item Scales", Journal for the Scientific Study of Religion, 28(3), ss.348-354.

Gorsuch, R.L. ve Venable, G.D. (1983), "Development of an "Age Universal" I-E Scale", Journal for the Scientific Study of Religion, 22(2), ss.181-187.

Greenberg, J. ve Baron, R.A. (2008). Behavior in Organizations, 9th. Edition, USA: Pearson Educational International.

Güney, S. (2012), Liderlik, İstanbul: Nobel Yayın Dağıtım.

Harrington, S.J. (1997), "A Test of A Person-Issue Contingent Model of Ethical Decision Making in Organizations", Journal of Business Ethics, 16(4),ss.363375.

Harrison, R. ve Stokes, H. (1992), Diagnosing Organizational Culture, Pfeiffer \& Co. 
Hart, S.L. ve Quinn, R.E. (1993), "Roles Executives Play: CEOs, Behavioral Complexity, and Firm Performance", Human Relations, 46(5), ss.543-574.

Hofstede, G. (1984), Culture's Consequences: International Differences in WorkRelated Values, Sage: Beverly Hills.

Hoobler, J.M. ve Hu, J. (2013), "A Model of Injustice, Abusive Supervision, and Negative Affect", The Leadership Quarterly, 24(1), ss.256-269.

Hoojberg, R. ve Petrock, F. (1993), "On Cultural Change: Using the Competing Values Framework to Help Leaders Execute a Transformational Strategy", Human Resource Management, 32(1), ss.29-50.

Huhtala, M., Kangas, M., Lamsa, A.M. ve Feldt, T. (2013), "Ethical Managers in Ethical Organisations? The Leadership-Culture Connection Among Finnish Managers", Leadership\&Organization Development Journal, 34(3), ss.250-270.

Hunt, R.A. ve King, M. (1971), "The Intrinsic-Extrinsic Concept: A Review and Evaluation", Journal for the Scientific Study of Religion, 10(4), ss.339-356.

Igo, T. ve Skitmore, M. (2006), "Diagnosing The Organisational Culture of an Australian Engineering Consultancy Using the Competing Values Framework", Construction Innovation, 6(2), ss.121-139.

İnanç, B.Y., ve Yerlikaya, E.E. (2012), Kişilik Kuramları, 6. Baskı, Ankara: Pegem Akademi Yayınları.

John, O.P., Donahue, E.M. ve Kentle, R.L. (1991), "The Big Five Inventory-Versions 4a and 54", Berkeley: University of California, Berkeley, Institute of Personality and Social Research.

Jones, T.M. (1991), "Ethical Decision Making by Individuals in Organizations: An IssueContingent Model", Academy of Management Review, 16(2), ss.366-395.

Judge, T.A. ve Bono, J.E. (2000), "Five-Factor Model of Personality and Transformational Leadership", Journal of Applied Psychology, 85(5), ss.751-765.

Judge, T.A., Bono, J.E., Ilies, R. ve Gerhardt, M.W. (2002), "Personality and Leadership: A Qualitative and Quantitative Review", Journal of Applied Psychology,.87(4), ss.765-780.

Kahoe, R.D. ve Meadow, M.J. (1981), "A Developmental Perspective on Religious Orientation Dimensions", Journal of Religion and Health, 20(1), ss.8-17.

Kalliath, T.J., Bluedorn, A.C. ve Gillespie, D.F. (1999), "A Confirmatory Factor Analysis of the Competing Values Instrument", Educational and Psychological Measurement, 59(1), ss.143-158.

Kalshoven, K., Den Hartog, D.N. ve De Hoogh, A.H.B. (2011), "Ethical Leader Behavior and Big Five Factors of Personality", Journal of Business Ethics, 100(2), ss.349-366.

Karabatı, S. (2012), "Örgütsel Davranışa Giriş" içinde Cemalcılar Z. (Ed.), Psikoloji, Eskişehir: Anadolu Üniversitesi Yayınları,.

Kennedy, E.J. ve Lawton, L. (1998), "Religiousness and Business Ethics", Journal of Business Ethics, 17, ss.163-175.

Kerr, J. ve Slocum, J.W. (1987), "Managing Corporate Culture Through Reward Systems", Teh Academy of Management Executive, 1(2), ss.99-107.

Koçel, T. (2005), İşletme Yöneticiliği, 10. Baskı, İstanbul: Arıkan Yayınları.

Kohlberg, L. ve Hersh, R.H. (1977), "Moral Development: A Review of the Theory", Theory into practise, 16 (2), ss.53-59.

Kreitner, R. ve Kinicki, A. (2008), Organizational Behavior, 8th. Edition, USA: McGraw Hill International Edition.

Kuzgun, Y. ve Sevim, S.A. (2004), "Kadınların Çalışmasına Karşı Tutum ve Dini Yönelim Arasındaki İlişki”, Ankara Üniversitesi Eğitim Bilimleri Fakültesi Dergisi, 37(1), ss.14-27. 
Küçüksille, E. (2010), "Çoklu Doğrusal Regresyon Modeli” içinde Ş. Kalaycı (Ed.), SPPS Uygulamalı Çok Değişkenli istatistik Teknikleri, 5. Baskı, Ankara: Asil Yayın Dağıtım.

Leonard, L.N., Cronan, T.P. ve Kreie, J. (2004), "What Influences IT Ethical Behavior Intentions- Planned Behavior, Reasoned Action, Perceived Importance, or Individual Characteristics?", Information \& Management, 42(1), ss.143-158.

Lumley, T., Diehr, P., Emerson, S. ve Chen, L. (2002), "The Importance of the Normality Assumption in Large Public Health Data Sets". Annu. Rev. Public Health, Vol.23, ss.151-69.

Marques, J.F. (2010), "Awakened Leaders: Who Are They and Why Do We Need Them?", Development And Learning in Organizations, 24(2), ss.7-10.

Martinko, M.J., Harvey, P., Sikora, D. ve Douglas, S.C. (2011), "Perceptions of Abusive Supervision: the Role of Subordinates' Attribution Styles", The Leadership Quarterly, 22(4), ss.751-764.

Mayer, D., Nishii, L., Schneider, B. ve Goldstein, H. (2007), "The Precursors and Products of Justice Climates: Group Leader Antecedents and Employee Attitudinal Consequences", Personnel Psychology, 60(4), ss.929-963.

McCrae, R.R. ve Costa, P.T. (1987), "Validation of the Five-Factor Model of Personality Across Instruments and Observers", Journal of Personality and Social Psychology, 52(1), ss.81-90.

Özkalp, E. ve Kırel, Ç. (2005), Örgütsel Davranış, Eskişehir: Anadolu Üniversitesi Yayınları.

Özyer, K. ve Azizoğlu, Ö. (2010), "Demografik Değişkenlerin Kişilerin Etik Tutumları Üzerindeki Etkileri", Ekonomik ve Sosyal Araştırmalar Dergisi, 6(2), ss.59-84.

Panayotopoulou, L., Bourantas, D. ve Papalexandris, N. (2003), "Strategic Human Resource Management and Its Effects on Firm Performance: An Implementation of the Competing Values Framework", Int. J. of Human Resource Management, 14(4), ss.680-699.

Quinn, R.E., Hildebrandt, H.W., Rogers, P.S. ve Thompson, M.P. (1991), “A Competing Values Framework for Analyzing Presentational Communication in Management Context", The Journal of Business Communication, 28(3), ss.213232.

Rest, J.E. (1984), "Research on Moral Development: Implications for Training Counseling Psychologists", The Counselling Psychologist, 12(3), ss.19-29.

Robbins, S.P. ve Judge, T.A. (2008), Essentials of Organizational Behavior, 9th. Edition, USA: Pearson International Edition.

Robertson, C. ve Fadil, P.A. (1999), "Ethical Decision Making in Multinational Organizations: A Culture-Based Model", Journal of Business Ethics, 19(4), ss.385-392.

Sackett, P.R. ve Wanek, J.E. (1996), "New Developments in the Use of Measures of Honesty Integrity, Conscientiousness, Dependability Trustworthiness, and Reliability for Personnel Selection", Personnel Psychology, 49(4), ss.787-829.

Schaubroeck, J., Walumbwa, F.O., Ganster, D.C. ve Kepes, S. (2007), "Destructive Leader Traits and the Neutralizing Influence of An "Enriched" Job", The Leadership Quarterly, 18(3), ss.236-251.

Schyns, B., ve Schilling, J. (2013), "How Bad Are the Effects of Bad Leaders? A Meta Analysis of Destructive Leadership and Its Outcomes", The Leadership Quarterly, 24(1), ss.138-158.

Seymen, O.A. ve Bolat, T. (2007), "Kohlberg'in Bilişsel Ahlaki Gelişim Modelinden Yararlanan Etiksel Karar Verme Modellerinin Karşılaştırmalı Analizi”, Akdeniz Üniversitesi IIIBF Dergisi, Sayı:13, ss.24-61.

Shih, M.L., Lin, S., Hsiao, S.H., Huang, L.M., Chiu, C. ve Chen, K.Y. (2009), "The Study of the Correlation Among Personality Traits, Leadership Competence and 
Organizational Performance", WSEAS Transactions on Business and Economics, 6(1), ss.10-20.

Strang, S.E. ve Kuhnert, K.W. (2009), "Personality and Leadership Developmental Levels as predictors of leader performance", The Leadership Quarterly, 20(3), ss.421-433.

Street, M.D., Douglas, S.C., Geiger, S.W. ve Martinko, M.J. (2001), "The Impact of Cognitive Expenditure on the Ethical Decision-Making Process: The Cognitive Elaboration Model", Organizational Behavior and Human Decision Processes, 86(2), ss.256-277.

Strong, K.C. ve Meyer, G.D. (1992), "An Integrative Descriptive Model of Ethical Decision Making", Journal of Business Ethics, 11(2), ss.89-94.

Sümer, N., Lajunen, T. ve Özkan, T. (2005), "Big Five Personality Traits as the Predictors of Road Accident Involvement", Traffic and Transport Psychology, Der. Underwood, G., 215-227, UK: Elsevier Publication.

Sweeney, P.D. ve McFarlin, D.B. (2002), Organizational Behavior - Solutions for Management, USA. McGraw Hill International Edition.

Şimşek, M.Ş. (2002), Yönetim ve Organizasyon. 7. Baskı, Konya: Günay Ofset.

Tabachnick, B.G. ve Fidell, L.S. (2007), Using Multivariate Statistics, 5th. Edition, USA, Boston: Pearson International Edition.

Tannenbaum, R. ve Schmidt, W.H. (1973), "How to Choose a Leadership Pattern", Harward Business Review, May-June, ss.3-12.

Taş, K. (2010), "Dindarlığa Yüklenen Anlamlar: Üniversite Öğrencileri Üzerine Uygulamalı Bir Araştırma”, Fırat Üniversitesi Ilahiyat Fakültesi Dergisi, 15(2), ss.47-62.

Tepper, B.J. (2000), "Consequences of Abusive Supervision", Academy of Management Journal, 43(2), ss.178-190.

Trevino, L.K. (1986), "Ethical Decision Making in Organizations: A Person-Situation Interactionist Model", Academy of Management Review, 11(3), ss.601-617.

Trevino, L.K., Hartman, L.P. ve Brown, M. (2000), "Moral Person and Moral Manager: How Executives Develop a Reputation for Ethical Leadership", California Management Review, 42(4), ss.128-142.

Tupes, E.C. ve Christal, R.E. (1992), "Recurrent Personality Factors Based on Trait Ratings", Journal of Personality, 60(2), ss.225-251.

Uğurluoğlu, Ö. ve Çelik, Y. (2009), “Örgütlerde Stratejik Liderlik ve Özellikleri”, Hacettepe Sağlık Idaresi Dergisi, 12(2), aa.121-156.

Van den Akker, L., Heres, L., Lasthuizen, K. ve Six, F. (2009), "Ethical Leadership and Trust: It's All About Meeting Expectations", International Journal of Leadership Studies, 5(2), ss.102-122.

Vilkinas, T. ve Cartan, G. (2006), "The Integrated Competing Values Framework: Its Spatial Configuration", Journal of Management Development, 25(6), ss.505-521.

Walumbwa, F.O. ve Schaubroeck, J. (2009), "Leader Personality Traits and Employee Voice Behavior: Mediating Roles of Ethical Leadership and Work Group Psychological Safety”, Journal of Applied Psychology, 94(5), ss.1275-1286.

Wong, H.M. (2008), "Religiousness, Love of Money, and Ethical Attitudes of Malaysian Evangelical Christians in Business", Journal of Business Ethics, 81, ss.169-191.

Yağmurlu, A. (1997), "Örgüt Kültürü: Tanımlar ve Yaklaşımlar”, Ankara Üniversitesi SBF Dergisi, 52(1), ss.717-724.

Yazıcıoğlu, Y. ve Erdoğan, S. (2007), SPSS Uygulamalı Bilimsel Araştırma Yöntemleri, 2. Baskı, Ankara: Detay Yayıncılık. 